\title{
Sustainable Food System and GM Foods in Era of Climate Change and Variability: Indian Perspective
}

\author{
RK Gupta*, Manoj Kumar and Anil Bhushan \\ Division of Vegetable Science and Floriculture, Sher-e-Kashmir University of Agricultural Sciences and Technology of Jammu, India
}

*Corresponding author: RK Gupta, Division of Vegetable Science and Floriculture, Sher-eKashmir University of Agricultural Sciences and Technology of Jammu, India.
Received Date: October 11, 2019

Published Date: October 21, 2019

\section{Opinion}

Agriculture and allied sectors are backbone of Indian economy. They are source of living for over 70 per cent of the population and provide around 50 per cent of employment in country. India has witnessed appreciable agriculture growth through crop improvement efforts, technological interventions and policy support. The food grain production has increased from 51MT (195051) to 285 MT (2018-19). Rice, wheat, pulses, oilseeds, sorghum, and maize are important field crops. The cotton and sugarcane are the principal commercial crops. Livestock and horticulture sectors have also contributed significantly in Agriculture GDP. India has one-half of the buffalo and one-sixth of the cattle population of the world. It ranks first in goat and sixth in sheep population besides vast potential of fishing resources.

India has huge challenges in terms of population growth that is likely to increase from existing around 1.3 billion to over 1.5 billion by 2050 . Average yields in many crops are generally $30-35 \%$ lower than highest average yield recorded in the world for various reasons. At same time, the availability of land, water and human resources is getting reduced for sustained agriculture for long term food and nutrition security. Moreover, agro-climate conditions in country are highly diverse, ranging from tropics in South to warm and temperate subtropics in North India. Two- thirds of the agriculture is rain fed and is prone to vagaries of weather. NE region receives very high rainfall while it is very low and erratic in West the rainfall. Arid zones occupy nearly 320,000 sq. km mainly in plains while cold desert of 84,000 sq. km exist in NW Himalayan region. The climate change and climatic aberrations have impacted production and productivity of field and horticultural crops across the country. The sustainable agricultural growth is crucial for the food security and overall economic development of the country.

Food security exists when all people always have access to enough, safe, nutritious food to maintain a healthy and active life. In simple words, food and nutrition security mean every individual has physical, social and economic access to balanced diet that includes macro and micronutrients, safe drinking water, environment hygiene, primary health care and education so as to lead healthy and productive life The conceptually, combination of the terms "sustainable" and "intensification" means producing more food, improving nutrition, and providing environmental goods and services. Sustainable intensification involves producing more total food (energy), feed, and nutritional components (protein, micronutrients, vitamins, etc.) on the existing land base with minimal adverse environmental impact while enhancing or conserving the natural resource base and biodiversity. Sustainable Intensification of Agriculture is the way forward for 'Food for Future' programs across the globe.

Sustainable Intensification (SI) is the way forward for producing more total food (energy), feed, and nutritional components (protein, micronutrients, vitamins, etc.) on the existing land base with minimal adverse environmental impact while enhancing or conserving the natural resource base and biodiversity. We need to reorient focus on Sustainable Food Systems (SFS) in order to enhance agricultural productivity, improve profitability and deliver food security while preserving or enhancing natural resource base from existing or lesser land in era of climate change and variation. India cannot afford to miss out on any technology that can possibly help in achieve a sustainable and productive agriculture system.

Major considerations for Sustainable Food Systems (SFS)

- Promote Sustainable intensification of agriculture in traditional irrigated belts using less water, a fewer agrochemicals and less fossil fuel.

- Enhance productivity in rain fed areas through efficient management of natural resources 
- Improve production and productivity in hill regions using traditional methods and eco-friendly technologies

- Diversify agriculture with horticulture, livestock and other allied sectors

- $\quad$ Reward farmers and farming community for preserving traditional knowledge and conservation of agro biodiversity

- Facilitate institutional credit support especially to women farmers and rural youth

- Ensure participation of all stake holders in decision making

- $\quad$ Provide policy support for increasing income of farmers by lowering inputs cost, efficient marketing and processing

- $\quad$ Free health facility to small and marginal farmers/farm labour and their family

- $\quad$ Free education to wards of small and marginal farmers/ farm labour

- Enhance total factor productivity and stability in production through sensible use of emerging technologies

- Increase public and private investment for technology development in agriculture and establishment of small and medium enterprises in potential pockets

- Generate rural employment for enhancing rural income and spending for better economy

- Promote ecological factors and stop man made over exploitation of natural resources

- $\quad$ Ensure food security of children for proper learning ability and better future human capital accumulation

Emerging technologies in agriculture evoke strong reactions, both for and against in India. It is now time to compliment traditional technologies with credible or proven technologies for improved agricultural productivity and profitability for overall sustainable food and nutrition security in era of climate change and variability in India. The positive outcomes from GM crops have been recorded in data analyzed from many publications in credible, peer-reviewed journals. More than 150 original studies based on primary data from farm surveys anywhere in the world reporting impact of GM soybean, maize or cotton on crop yields, pesticide use, and farm profits have shown reduced pesticide use by $30 \%$, increased crop yields by $20 \%$ and increased farmer profits by $50 \%$. Yield and profit gains were reported higher in GM cotton in India when compared with many countries. With aspirations to ensure food and nutrition security to over 1.3 billion people and more than 500 million livestock (excluding poultry), India needs to assess rationally on a case-to-case basis new technologies or new GM crops about safety of human health and environment before adoption.

Globally, a consensus has not been possible on benefit and risk of GM crops. Often the negative perceptions have not been based on sound scientific evidences. Data on livestock from publicly available sources, starting from the year 1983 and representing over 100 billion animals did not reveal unfavorable or perturbed trends in livestock health and productivity after the introduction of GM cropfeeds. A group of Nobel laureates have also appealed to Greenpeace during 2016 to rethink its longstanding opposition to genetically modified organisms. For Sustainable Food Systems (SFS), scientists need space to find out solutions and access new technologies in order to address emerging concerns in era of climate change and climate variability.

\section{Acknowledgement}

None.

\section{Conflict of Interest}

No conflict of interest. 